\title{
Clinicopathologic differences and mortality among Latinos and non-Latino whites with gastric cancer at a majority-minority cancer center in South Texas
}

\author{
Madison H. Williams ${ }^{1}$, Ryan A. Williams ${ }^{1}$, Brian Hernandez ${ }^{2}$, Joel Michalek ${ }^{2}$, Dorothy Long Parma ${ }^{2}$, \\ Sukeshi P. Arora ${ }^{1}$ \\ ${ }^{1}$ Division of Hematology/Oncology, Department of Internal Medicine, Mays Cancer Center, University of Texas Health San Antonio, San Antonio, \\ TX, USA $;{ }^{2}$ Department of Population Health Sciences, Mays Cancer Center, University of Texas Health San Antonio, San Antonio, TX, USA \\ Contributions: (I) Conception and design: SP Arora; (II) Administrative support: None; (III) Provision of study materials or patients: None; (IV) \\ Collection and assembly of data: MH Williams, SP Arora; (V) Data analysis and interpretation: All authors; (VI) Manuscript writing: All authors; (VII) \\ Final approval of manuscript: All authors. \\ Correspondence to: Sukeshi P. Arora. Associate Professor, Leader in Gastrointestinal Malignancies, Mays Cancer Center, University of Texas Health \\ San Antonio, 7979 Wurzbach Rd, San Antonio, TX 78229, USA. Email: aroras@uthscsa.edu.
}

Background: Latino patients have a higher incidence of gastric cancer compared to non-Latino white patients nationwide, with greater disparities in South Texas. However, the impact of Latino ethnicity on mortality in gastric cancer is controversial. We evaluated clinicopathological characteristics and survival outcomes in Latino vs. non-Latino white patients at our National Cancer Institute (NCI)-designated cancer center and its affiliated hospital.

Methods: We conducted a retrospective chart review of Latino and non-Latino white patients diagnosed with gastric cancer who were seen at Mays Cancer Center at the University of Texas Health in San Antonio, Texas, from 2000-2018. Median overall survival (mOS) was estimated from Kaplan-Meier curves and groups were compared with the log-rank test.

Results: A total of 193 patients met inclusion criteria and 65\% ( $n=126)$ were Latino. Median age for all patients was 61 years. Female patients represented almost $50 \%$ of Latinos $v$ s. $36 \%$ of non-Latino whites. There were no differences in Eastern Cooperative Oncology Group (ECOG) performance status, primary tumor location, stage, Helicobacter pylori status, HER2 status, or histologic subtype at diagnosis. Median overall survival was 14 months (95\% CI: 13-36) for Latinos vs. 33 months (95\% CI: 14 to n/a) for nonLatino whites $(\mathrm{P}=0.36)$.

Conclusions: Compared to non-Latino white patients, Latino patients with gastric cancer at a majorityminority cancer center in South Texas did not have significant differences in baseline clinicopathologic features or survival outcomes. Further prospective studies are needed to evaluate epidemiologic, pathogenetic, and molecular differences in gastric cancer in order to identify variables associated with treatment efficacy and survival.

Keywords: Gastric cancer; Latino; Hispanic; older adult; elderly

Submitted Jan 21, 2021. Accepted for publication Jun 30, 2021.

doi: 10.21037/jgo-21-39

View this article at: https://dx.doi.org/10.21037/jgo-21-39 


\section{Introduction}

Latinos currently represent the largest minority group in the United States (US). In 2016, nearly 60 million Americans identified as Hispanic or Latino (1). According to US Census Bureau projections, this ethnic group will double by the year 2060 (2). Texas is home to $19 \%$ of the nation's Latino population, with the vast majority of Latino Texans being of Mexican origin (1).

Gastric adenocarcinoma is the predominant form of gastric cancer. Wang et al. conducted a large retrospective study using US Cancer Statistics (USCS) registry and Surveillance, Epidemiology, and End Results (SEER) Program data to examine national and state-level trends in gastric cancer incidence (3). This study demonstrated an overall reduction in the incidence of gastric cancer, from 7.64 per 100,000 in 1999 to 6.55 per 100,000 in 2013. However, they noted decreases in the rate of decline from 2007 onward and there was an increase in incidence rates amongst younger adults (those under age 50), particularly in females. California and Texas, states with large and growing Latino populations, showed the highest annual increases in the incidence of gastric cancer. However, it is important to note that the SEER data used in this study did not include patients from Texas.

To date, there is a paucity of published research on gastric cancer disparities in South Texas. Based on 2005-2009 Texas Cancer Registry and 2004-2008 SEER-17 data, the age-adjusted incidence rate (per 100,000) of gastric cancer is higher for South Texas compared to the rest of the state of Texas and the nation (8.3 vs. $6.7 v s .7 .7$, respectively) (4). Additionally, gastric cancer occurrence is more than two times higher among South Texas Latinos than in nonLatino whites (11.4/100,000 vs. 4.7/100,000). Moreover, in South Texas, the incidence rate of gastric cancer is roughly twice as high among Latino females compared to nonLatino white females. Considering these observations in a Latino majority-minority region, it is critical to elucidate contributing factors for gastric cancer mortality in order to appropriately manage this high-risk group.

Results from other regional studies may not be applicable to South Texas considering differences in the composition of study populations and other lifestyle and environmental factors specific to the geographic area $(5,6)$. Thus, research efforts to explore demographic, clinical, and histopathologic features as well as survival outcomes in gastric cancer among a distinctive population in South Texas is warranted. In contrast to other gastric cancer studies in the US, the
Latino community in our investigation is more homogenous (i.e., of Mexican origin) and constitutes the majority of the patient population under examination (7). The objective of our study was to compare clinicopathological characteristics and survival outcomes of Latino and non-Latino white patients with gastric cancer who were seen at the National Cancer Institute (NCI)-designated Mays Cancer Center at the University of Texas (UT) Health San Antonio. We present the following article in accordance with the STROBE reporting checklist (available at https://dx.doi. org/10.21037/jgo-21-39).

\section{Methods}

\section{Setting and data sources}

The study was conducted in accordance with the Declaration of Helsinki (as revised in 2013). The study was deemed exempt by the Institutional Review Board at UT Health San Antonio and informed consent for this retrospective analysis was waived. We performed a retrospective chart review of all patients with gastric adenocarcinoma diagnosed and treated at Mays Cancer Center between 2000-2018. Data was entered directly into the Research Electronic Data Capture (REDCap) system, a web-based survey administration and data collection service developed at Vanderbilt University and hosted by the Department of Population Health Sciences (8).

\section{Statistical analyses}

The primary outcome measure was overall survival. Covariates included demographic data such as age at diagnosis, ethnicity, gender, and family history of cancer; clinical data including pathologic stage at diagnosis according to the American Joint Committee on Cancer (AJCC) (9), clinical stage at diagnosis, and treatment type (i.e. surgery, chemotherapy, radiation); and histopathological criteria including tumor grade, type-Lauren classification, lymph node involvement, anatomic location of primary tumor, lymphovascular invasion (LVI), Helicobacter pylori (H. pylori) status, HER2 status, and location of metastases. Continuously distributed outcomes were summarized with the sample size, mean, standard deviation, median, minimum and maximum and categorical outcomes were summarized with frequencies and percentages. Groups were contrasted on the mean with $t$-tests and on the median with Wilcoxon tests, and on proportions with Pearson's 
Table 1 Baseline patient characteristics

\begin{tabular}{lccc}
\hline Characteristics & All patients & Latino & Non-Latino Whites \\
\hline Total patients, n (\%) & 193 & $126(65.3)$ & $67(34.7)$ \\
Median age (years) & 59.2 & 58.8 & 59.9 \\
Gender, n (\%) & & & \\
Male & $108(56.0)$ & $65(51.6)$ & $43(64.2)$ \\
Female & $85(44.0)$ & $61(48.4)$ & $24(35.8)$ \\
ECOG PS, n (\%) & & & \\
0-2 & $119(61.7)$ & $78(61.9)$ & $41(61.2)$ \\
3-4 & $10(5.2)$ & $7(5.6)$ & $3(4.5)$ \\
Missing & $64(33.2)$ & $41(32.5)$ & $23(34.3)$ \\
\hline
\end{tabular}

ECOG PS, Eastern Cooperative Oncology Group performance status; $n$, number of patients.

Chi-square or Fisher's exact tests as appropriate. Groups were contrasted on survival with $\log$ rank tests and survival distributions were described with Kaplan-Meier curves with $95 \%$ confidence bands. All statistical testing was twosided with a significance level of $5 \%$ and $95 \%$ CIs for mean differences and for the median time to death. $\mathrm{R}$ was used throughout.

\section{Results}

At our institution, 193 patients with gastric adenocarcinoma were diagnosed and treated between 2000-2018. Our patient population was predominantly Latino with 126 (65.3\%) Latino patients and 67 (34.7\%) non-Latino white patients (Table 1). The median ages were 58.8 years and 59.9 years for Latino and non-Latino white patients, respectively. Most patients were male $(51.6 \%$ of Latino patients and $64.2 \%$ of non-Latino white patients). The majority of patients had an Eastern Cooperative Oncology Group (ECOG) performance status of $0-2$ in both ethnic groups (61.9\% for Latino patients vs. 61.2\% for non-Latino white patients). The majority of this population was not tested for $H$. pylori, however, of those tested, most were negative. There were no significant differences in ECOG performance status at diagnosis or $H$. pylori status between the two groups.

For both groups, the most common location for primary tumor site was the gastric body $(32.5 \%$ for Latinos $v s$. $37.3 \%$ for non-Latino whites), followed closely by the antrum $(28.6 \%$ for Latinos vs. $20.9 \%$ for non-Latino whites) (Table 2). There was no difference in location of metastases, with both groups most frequently metastasizing to the liver (11.9\% in both Latinos and non-Latino whites). There were also no significant differences in tumor grade between the two groups, with each group most commonly presenting with poorly differentiated tumors $(55.6 \%$ for Latinos vs. $47.7 \%$ for non-Latino whites). Most patients in our population presented with metastatic disease with $42.9 \%$ of Latinos and $44.8 \%$ of non-Latino whites having stage IV disease at diagnosis. More Latino patients presented with stage III gastric cancer than non-Latino whites with $17.5 \%$ vs. $7.5 \%$, respectively, although this was not a statistically significant difference. The most common histologic subtype in both Latino and non-Latino groups was the diffuse type. For the majority of our population, HER2 expression was unknown. However, for Latinos immunohistochemistry (IHC) was positive (3+) for 5.6\% and fluorescence in-situ hybridization (FISH) was positive in $4 \%$. For non-Latino whites, IHC was positive in $0 \%$ and FISH was positive in $4.5 \%$. There were no significant differences in stage at diagnosis, primary tumor location, histologic subtype, or HER2 status between the two groups.

The majority of the 85 female patients included in the study were Latina, with 61 (71.8\%) Latina females and $24(28.2 \%)$ non-Latina white females. There was no statistically significant difference in median age of female patients between the two ethnic groups. However, a higher percentage of Latina females were age 65 and older compared to non-Latina white females $(27.9 \%$ vs. $16.7 \%)$. Most female patients in both ethnic groups had an ECOG performance status of $0-2$ at diagnosis $(58.3 \%$ nonLatina white females and $63.9 \%$ Latina females). A higher percentage of Latina females presented with an ECOG performance status of 3 , although this was not a statistically significant difference. More Latina females presented with locally advanced or metastatic disease $(55.7 \%)$ when compared to non-Latina white females (45.8\%), however, this did not represent a statistically significant difference.

As with the overall study population, the majority of the 108 male patients included were Latino, with 65 (60.2\%) Latino males and 43 (39.8\%) non-Latino white males. There was no statistically significant difference in the age of Latino and non-Latino white males, with a median age of $60.8 v s .61 .9$, respectively. The majority of male patients in both ethnic groups had an ECOG performance status of 0-2 at the time of diagnosis $(62.8 \%$ non-Latino white males and $60 \%$ Latino males). When compared to non-Latino white males, more Latino males presented with locally advanced 
Table 2 Baseline disease characteristics

\begin{tabular}{|c|c|c|c|c|}
\hline Characteristics & All patients $(n=193), n(\%)$ & Latino $(n=126), n(\%)$ & Non-Latino Whites $(n=67), n(\%)$ & $P$ value \\
\hline Gastric body & $66(34.2)$ & $41(32.5)$ & $25(37.3)$ & \\
\hline Antrum & $50(25.9)$ & $36(28.6)$ & $14(20.9)$ & \\
\hline Gastroesophageal Junction & $33(17.1)$ & $20(15.9)$ & $13(19.4)$ & \\
\hline Fundus & $9(4.7)$ & $6(4.8)$ & $3(4.5)$ & \\
\hline Unknown & $23(11.9)$ & $14(11.1)$ & $9(13.4)$ & \\
\hline Location of metastases & & & & 0.71 \\
\hline Liver & $23(11.9)$ & $15(11.9)$ & $8(11.9)$ & \\
\hline Other & $65(33.7)$ & $45(35.7)$ & $20(29.9)$ & \\
\hline No metastases & $87(45.1)$ & $56(44.4)$ & $31(46.3)$ & \\
\hline Grade & & & & 0.80 \\
\hline Moderate-well differentiated & $54(28.0)$ & $37(29.4)$ & $17(25.4)$ & \\
\hline Poorly differentiated & $102(52.8)$ & $70(55.6)$ & $32(47.8)$ & \\
\hline Unknown & $37(19.2)$ & $19(15.1)$ & $18(26.9)$ & \\
\hline Stage & & & & 0.49 \\
\hline I-II & $53(27.5)$ & $36(28.6)$ & $17(25.4)$ & \\
\hline Other & $34(17.6)$ & 20 (15.9) & $14(21)$ & \\
\hline Unknown & $71(36.8)$ & $43(34.1)$ & $28(41.8)$ & \\
\hline H. pylori status & & & & 0.76 \\
\hline Positive & $14(7.3)$ & $10(7.9)$ & $4(6.0)$ & \\
\hline Negative & $58(30.1)$ & $38(30.2)$ & 20 (29.9) & \\
\hline Unknown & $121(62.7)$ & $78(61.9)$ & $43(64.2)$ & \\
\hline
\end{tabular}

n, number of patients.

or metastatic disease $(64.6 \%$ vs. $55.8 \%)$.

The median overall survival (mOS) was 14 months (95\% CI: 13-36) for Latino patients vs. 33 months (95\% CI: 14 to NR) for non-Latino white patients
$(\mathrm{P}=0.36)$ (Figure 1). Although there was not a statistically significant difference in mOS, there was a trend toward improved survival in non-Latino white patients compared to Latino patients. 


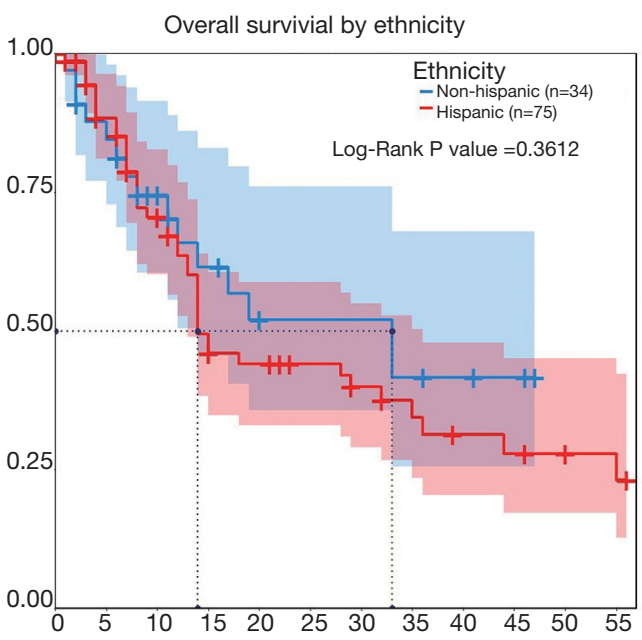

Figure 1 Median overall survival in months by ethnicity. n, number.

\section{Discussion}

In this retrospective analysis of predominantly Latino patients with gastric cancer, we found that there were no statistically significant differences in clinicopathologic features at diagnosis. We also did not find significant differences in survival between the two ethnic groups. However, we did find that there is a trend towards decreased survival in Latino patients when compared to non-Latino white patients. Although we did not find a statistically significant difference, our trend does appear to be consistent with what some other studies have been able to demonstrate, with inferior outcomes in Hispanic patients with gastric cancer (10).

There are, however, other studies which have not been able to demonstrate a propensity for Latinos to have worse survival outcomes than non-Latino whites. This may be due, in part, to the diverse nature of the Latino population. Just over two-thirds of Latinos were born in the US (11), yet they are often grouped together with foreign-born Latinos in studies. It has been demonstrated that foreign-born Latinos have lower mortality rates for all cancers combined when compared with non-Latino whites (12). However, Latinos born in the US have cancer mortality rates approaching that of non-Latinos. This effect could be attributed to a higher propensity of healthy individuals to migrate to the US, or to an assimilation of cultural and dietary habits that may lead to higher risk disease in US-born patients. For these reasons, other studies have sought to divide the Latino population into those who were born in the US and those who were born in other countries. One study that made this distinction demonstrated inferior outcomes in Latino patients with gastric cancer overall (12). When these populations were stratified by country of birth, the findings became more complex, as the outcomes varied depending on the state of birth, with California-born patients having better outcomes than those that were Texas-born.

Even though overall cancer mortality is lower for foreignborn Latinos, gastric cancer is one of the few malignancies where Latino patients have worse mortality rates than non-Latinos overall (10). Other researchers have also hypothesized that disease biology is inherently different in Latino patients. For example, increased prevalence of Epstein-Barr virus (EBV) and H. pylori-related gastric cancer in this population might contribute to differing outcomes in these studies as well. The disease biology appears to have multiple complex factors contributing. EBV appears to be associated more frequently with more positive outcomes (13). EBV-associated gastric cancers have also been demonstrated to be more common in Hispanic patients in a small study (14), although more prospective evaluation is required to further clarify these data. Non-cardia diffuse-type gastric cancer is a subtype that is associated with treatment resistance and poorer outcomes (15). This type of gastric cancer is more common in those with lower socioeconomic status (16), and thus this is thought to also be a possible driver of disparate outcomes between non-Latinos and minority populations in the US.

Lower socioeconomic status has also been linked to poorer access to quality care, including lower rates of screening, delays in treatment after diagnosis, and low adherence to treatment plans (17). In addition to being overrepresented in this category (18), the US Latino population is the least insured group in the country (19), which could also be linked with inferior outcomes. Counteracting this is the fact that there may be an earlier median age at diagnosis of gastric cancer in Latinos. In one study of 129,666 Latino patients diagnosed with gastric cancer between 2004 and 2014, the median age of diagnosis was 63 for Hispanics vs. 69 for non-Hispanics (20), making outcomes even more difficult to compare. Thus, there are many complex and sometimes conflicting factors that determine outcomes in this patient population.

Limitations of our study include that it is a retrospective analysis and it is a relatively small sample size. Additionally, our study population had a low rate of HER2 testing which is in part due to the inclusion of non-metastatic patients 
and that our study period included a time frame that begins prior to HER2 testing becoming standard of care. Our study also did not make the distinction between US and foreign-born Latinos, which could guide the direction of future studies. Given the limited published research available for this patient population, further prospective real-world studies are needed to evaluate access to care, quality of life, and treatment outcomes in order to improve the care of Hispanic patients with gastric cancer. We also need further investigation of epidemiologic, pathogenetic, and molecular differences to help identify variables that are predictive of treatment efficacy and survival outcomes.

\section{Acknowledgments}

All authors appreciate the efforts of Cesar Barron, MD, for his work in starting this project.

Funding: This work was supported by National Institutes of Health (grant number CA054174).

\section{Footnote}

Reporting Checklist: The authors have completed the STROBE reporting checklist. Available at https://dx.doi. org/10.21037/jgo-21-39

Data Sharing Statement: Available at https://dx.doi. org/10.21037/jgo-21-39

Conflicts of Interest: All authors have completed the ICMJE uniform disclosure form (available at https://dx.doi. org/10.21037/jgo-21-39). Dr. SPA declares that she is on the Speakers Bureau for Bayer and Exelixis. She has received honoraria for lectures (Haymarket CME Education, Horizon CME Education). She has participated on Advisory Boards for AstraZeneca and QED Therapeutics. She has received support for travel from Faron. She is on the board for Support New India (unpaid). Dr. DLP declares that she has a relationship with the Department of Defense PRCRP, whose Career Development Award provided protected time to work on this manuscript. The other authors have no conflicts of interest to declare.

Ethical Statement: The authors are accountable for all aspects of the work in ensuring that questions related to the accuracy or integrity of any part of the work are appropriately investigated and resolved. The study was conducted in accordance with the Declaration of Helsinki (as revised in 2013). The study was deemed exempt by the Institutional Review Board at UT Health San Antonio and informed consent for this retrospective analysis was waived.

Open Access Statement: This is an Open Access article distributed in accordance with the Creative Commons Attribution-NonCommercial-NoDerivs 4.0 International License (CC BY-NC-ND 4.0), which permits the noncommercial replication and distribution of the article with the strict proviso that no changes or edits are made and the original work is properly cited (including links to both the formal publication through the relevant DOI and the license). See: https://creativecommons.org/licenses/by-nc-nd/4.0/.

\section{References}

1. American Cancer Society. Cancer Facts and figures for Hispanics/Latinos 2018-2020. Atlanta: American Cancer Society, Inc. 2018. Available online: https://www.cancer. org/content/dam/cancer-org/research/cancer-factsand-statistics/cancer-facts-and-figures-for-hispanicsand-latinos/cancer-facts-and-figures-for-hispanics-andlatinos-2018-2020.pdf.

2. U.S. Census Bureau. 2017 National Population Projections Tables. National Population Projections. Available online: https://www.census.gov/data/tables/2017/demo/ popproj/2017-summary-tables.html

3. Wang Z, Graham DY, Khan A, et al. Incidence of gastric cancer in the USA during 1999 to 2013: a 50-state analysis. Int J Epidemiol 2018;47:966-75.

4. Ramirez AG, Thompson IM, Vela L. The South Texas health status review: A health disparities roadmap. Switzerland: Springer International Publishing, 2013:138.

5. Duma N, Sanchez LJ, Castro YS, et al. Gastric adenocarcinoma: clinicopathologic differences among Hispanics and non-Hispanic whites. A single Institution's experience over 14 years. Ann Gastroenterol 2016;29:325-31.

6. Klapheke AK, Carvajal-Carmona LG, Cress RD. Racial/ ethnic differences in survival among gastric cancer patients in california. Cancer Causes Control 2019;30:687-96.

7. Pew Research Center. Demographic and economic profiles of Hispanics by state and county, 2014. Available online: https://www.pewresearch.org/hispanic/states/state/tx

8. Harris PA, Taylor R, Thielke R, et al. Research electronic data capture (REDCap)--a metadata-driven methodology 
and workflow process for providing translational research informatics support. J Biomed Inform 2009;42:377-81.

9. Amin MB, Edge S, Greene F, et al., editors. AJCC Cancer Staging Manual. 8th ed. New York: Springer, 2017.

10. Lui FH, Tuan B, Swenson SL, et al. Ethnic disparities in gastric cancer incidence and survival in the USA: an updated analysis of 1992-2009 SEER data. Dig Dis Sci 2014;59:3027-34.

11. Noe-Bustamante L, Flores A. Facts on Latinos in the US. Pew Research Center Hispanic Trends. Available online: https://www.pewresearch.org/hispanic/fact-sheet/latinosin-the-u-s-fact-sheet/

12. Pinheiro PS, Callahan KE, Gomez SL, et al. High cancer mortality for US-born Latinos: evidence from California and Texas. BMC Cancer 2017;17:478.

13. Sohn BH, Hwang JE, Jang HJ, et al. Clinical Significance of Four Molecular Subtypes of Gastric Cancer Identified by The Cancer Genome Atlas Project. Clin Cancer Res 2017. doi: 10.1158/1078-0432.CCR-16-2211. [Epub ahead of print].

14. Ramirez AG, Trapido E, editors. Advancing the science of cancer in Latinos. Switzerland: Springer International

Cite this article as: Williams MH, Williams RA, Hernandez B, Michalek J, Long Parma D, Arora SP. Clinicopathologic differences and mortality among Latinos and non-Latino whites with gastric cancer at a majority-minority cancer center in South Texas. J Gastrointest Oncol 2021;12(4):1301-1307. doi: 10.21037/ jgo-21-39
Publishing, 2019.

15. Miller KD, Goding Sauer A, Ortiz AP, et al. Cancer Statistics for Hispanics/Latinos, 2018. CA Cancer J Clin 2018;68:425-45.

16. Gupta S, Tao L, Murphy JD, et al. Race/Ethnicity-, Socioeconomic Status-, and Anatomic Subsite-Specific Risks for Gastric Cancer. Gastroenterology 2019;156:5962.e4.

17. Siegel RL, Miller KD, Jemal A. Cancer statistics, 2019. CA Cancer J Clin 2019;69:7-34.

18. Williams DR, Priest N, Anderson NB. Understanding associations among race, socioeconomic status, and health: Patterns and prospects. Health Psychol 2016;35:407-11.

19. Berchick ER, Barnett JC, Upton RD. Current population reports, P60-267(RV). Health Insurance Coverage in the United States: 2018. Washington, DC: US Government Printing Office, 2019.

20. Zhao B, Leichman LP, Horgan S, et al. Evaluation of treatment and outcomes for Hispanic patients with gastric cancer at Commission on Cancer-accredited centers in the United States. J Surg Oncol 2019;119:941-7. 